\title{
Relationship between electrical activity of the uterus and surgically isolated myometrium in the pregnant and non- pregnant ewe
}

\author{
J. N. Sigger, R. Harding and G. Jenkin \\ Department of Physiology, Monash University, Clayton, Victoria 3168, Australia
}

\begin{abstract}
Summary. Rhythmic contractions occur in the sheep uterus at oestrus and during pregnancy from about 65 days to term (145 days). To define factors responsible for these contractions we have examined and quantified the degree of synchronization of electrical activity in the uterus and isolated segments of myometrium in 3 types of experiments. In the first, a segment of myometrium was totally separated from the uterus. After a period of 9-16 days the isolated tissue developed a typical pattern of uterine activity which showed no significant degree of synchronization with EMG bursts in the body of the uterus. During labour, the isolated tissue showed changes in activity similar to those observed in the uterus. In the 2 nd experiment, the tubal end of one of the uterine horns was severed from the uterus, but a connection was retained with the uterus via the oviduct and ovarian blood vessels. Activity in the partly isolated segment remained in synchrony with the uterus. In a 3rd experiment, impulse propagation through nerves and smooth muscle to the tip of a horn was disrupted by severing 'the tip' from the uterus while its blood supply from the ovarian vessels was retained. The blood vessels were momentarily frozen, and denervation confirmed by monoamine histofluorescence. In 5 out of 6 animals the operated tissue showed activity that was not synchronous with the rest of the uterus. These data indicate that: (1) isolated uterine muscle in vivo has rhythmicity resembling that of intact myometrium and (2) systemic or local circulating factors are not responsible for synchronizing uterine activity before parturition, although circulating factors do play a major role in increasing the uterine activity which occurs at parturition and at oestrus, and (3) hydraulic continuity between different regions of the uterus is not essential for maintaining co-ordinated activity.
\end{abstract}

\section{Introduction}

Uterine contractions before parturition are known to occur in a number of species including guinea-pigs (Porter, 1971); sheep (Hindson \& Ward, 1973); monkeys (Germain, Cabrol, Visser \& Sureau, 1982) and man (Csapo \& Sauvage, 1968). The rise in intrauterine pressure which is associated with these contractions indicates the presence of co-ordinated electrical activity in the smooth muscle of the uterus, and this has been demonstrated by electromyographic techniques (Harding et al., 1982a). In guinea-pigs and women a substantial reduction takes place during pregnancy in the transmitter content of adrenergic nerves innervating the uterus (see Marshall, 1981). The innervation in guinea-pigs degenerates and by mid-pregnancy the smooth muscle of the 
uterus appears to be effectively denervated. In-vitro experiments on progesterone-dominated rat and rabbit myometrium have demonstrated multiple pacemaker sites within the uterus and poor propagation of electrical activity through the smooth muscle (Marshall, 1959, 1962; Ichikawa \& Bortoff, 1970). In the late pregnant pig, synchronous electrical activity occurs in regions of the uterus occupied by fetuses, but the remainder of the uterus is relatively inactive (Taverne $e t$ al., 1979a). During parturition, the site at which uterine activity initially appeared, and its rate of propagation, were variable (Taverne, Naaktegeboren \& van der Weyden, 1979b). The way in which the myometrial pacemakers are regulated and co-ordinated to generate the uterine contractions characteristic of late pregnancy and parturition is unknown.

Harding et al. (1982a) performed experiments on 2 pregnant ewes in which the tubal extremity of one uterine horn was isolated leaving it attached to the uterus only by the broad ligament and ovarian blood vessels. Activity in this partly isolated tissue remained in synchrony with the uterus. We have extended this study to investigate whether systemic or locally circulating substances are responsible for co-ordinating uterine contractions. Preliminary observations have been published (Harding, Jenkin \& Sigger, 1982b).

\section{Materials and Methods}

Three non-pregnant cyclic ewes ( 1 crossbred, 2 Merino) and 15 pregnant crossbred ewes were used in these experiments. Food was withdrawn $24 \mathrm{~h}$ before surgery for which the ewes were anaesthetized with halothane $\left(2-3 \%\right.$ halothane in $\left.\mathrm{O}_{2}\right)$. The uterus was exposed by a midline laparotomy.

\section{Electromyographic electrodes}

Pairs of electrodes constructed from insulated multistranded stainless-steel wire (Cooner Sales Co., U.S.A., Cat. No. AS632) were used to detect activity in the myometrium of the uterus and surgically isolated uterine segments (Nathanielsz, Bailey, Poore, Thorburn \& Harding, 1980). A pair of electrodes was sewn into the muscle in a way which left a $1.0-1.5 \mathrm{~mm}$ bare portion of the wire within the muscle. The uterine electromyogram (EMG) was recorded in each animal using two or more pairs of electrodes sewn into the myometrium at sites on the greater curvature of a horn and the corpus. Two additional pairs of electrodes were also sewn into the myometrium of each of the isolated uterine segments, and a single reference electrode was sewn into the uterus.

Intrauterine pressure (IUP) was recorded using a fluid-filled balloon-tipped (20 mm $\times 3 \mathrm{~mm}$ ) catheter inserted into the uterine lumen of the non-pregnant ewes, or a saline-filled open-tipped catheter in the amniotic sac of the pregnant ewes. Each catheter was coupled to a Statham P23 ID pressure transducer. Recordings of IUP were compared with uterine EMG to aid identification of uterine contractions. The catheter and electrode leads were exteriorized via an incision in the flank of the ewe. Signals were amplified and displayed using an 8-channel Grass polygraph with highpass filtering set at $3 \mathrm{~Hz}$ on the EMG channels. Recordings were started on the first day after surgery and were continued at least every 3 rd day after this time. In 10 of the ewes, the fetuses were instrumented for other experiments; a study by Harding et al. (1982b) detected no differences in uterine activity between ewes carrying instrumented fetuses and ewes in which the uterus was not incised.

\section{Surgical isolation of uterine segments}

Three types of experimental preparation were used in this study. All were based on the isolation or partial isolation of small segments of uterine tissue.

(1) Tissue completely isolated from uterus (Text-fig. 1a). In 7 sheep ( 3 non-pregnant, 4 pregnant) $20-30 \mathrm{~mm}$ of the tubal extremity of one uterine horn was isolated by severing it from the uterus, and 
(a)
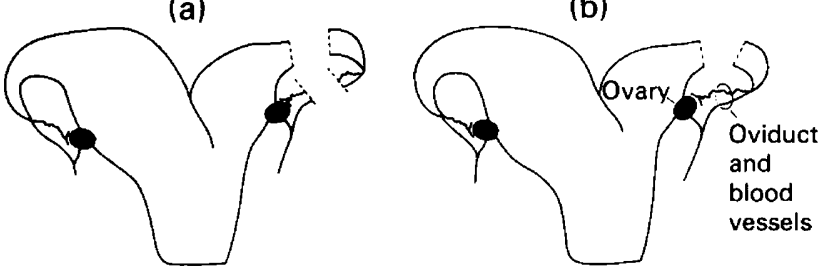

(c)

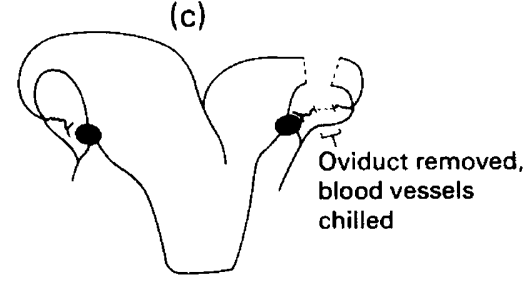

Text-fig. 1. Diagrams of the three experimental preparations. See text for further details. (a) Tubal extremity of uterine horn completely isolated from uterus. (b) Tubal extremity partly isolated but retaining a connection with the uterus via the broad ligament, oviduct and the uterine branches of the ovarian blood vessels. (c) Tubal extremity which retained its original blood supply from the ovarian artery and vein. In 5 out of 7 animals these vessels were denervated by chilling. The oviduct and broad ligament were removed.

from the oviduct and ovarian blood vessels. The muscle layers of the uterine horn and, when appropriate, the fetal membranes, were closed with sutures. Two pairs of EMG electrodes were sewn into the isolated tip which was then enclosed in a pocket of omental fat in a way that prevented it from making contact with the remainder of the uterus. In 2 non-pregnant ewes the isolated tubal extremity was placed in a previously prepared skin loop in the neck which also enclosed a carotid artery. A strip of myometrium, about $5 \mathrm{~mm} \times 25 \mathrm{~mm}$, from the body of the uterus and a segment from the isthmic region of the oviduct were isolated in a similar manner to the tip of the uterine horn in 2 and 1 pregnant ewes, respectively. At post-mortem examination the isolated tissues were found to have established blood supplies with vessels supplying the omental fat, or in the carotid loop sites, with vessels in the skin of the loop.

(2) Tissue partly isolated from uterus (Text-fig. 1b). In 4 pregnant ewes the tubal extremity was separated from the non-pregnant horn by cutting through the myometrium and endometrium, but a connection was retained with the uterus via the broad ligament, oviduct and ovarian blood vessels. After sewing in two pairs of EMG electrodes the 'semi-isolated' tissue was encased in a pocket of omental fat to prevent it making direct contact with the uterus. In addition, in 2 pregnant ewes the tubal extremity was separated from the non-pregnant horn, but the oviduct was removed, leaving the tissue attached to the uterus by the ovarian blood vessels alone. This operation is described in detail in the following section.

(3) Tissue partly isolated from uterus, blood vessels chilled (Text-fig. 1c). This experimental preparation was designed to isolate the tip of the horn from propagated electrical activity along nerves or smooth muscle whilst retaining the original blood supply. The tips of the uterine horns receive most of their blood supply from branches of the ovarian artery and vein which run alongside the oviduct in the broad ligament (Del Campo \& Ginther, 1973). The ovarian blood vessels supplying the tip of one horn were carefully separated from the oviduct and broad ligaments for a distance of 25-30 mm. The isthmic region of the oviduct was severed at the utero-tubal junction and removed. The tubal extremity of the horn was then separated from the uterus. The blood vessels supplying the isolated tip were momentarily frozen at 4-5 sites along their length using a stainlesssteel probe chilled in liquid $\mathrm{N}_{2}$. The chilling initially caused the tissue to become cyanosed but red coloration returned within 2-3 min. After the blood vessels had been chilled, two pairs of EMG electrodes were sewn into the myometrium of the isolated tissue. The isolated segment was then wrapped in a pocket of omental fat, care being taken not to exert undue tension on the ovarian blood vessels. This operation was performed on 5 pregnant ewes, in one of which the contralateral tubal extremity was partly isolated but not chilled. A slightly different operation was performed on a 6th ewe. In this animal the oviduct and ovarian blood supply to the tubal extremity were removed. The tip of the horn was separated from the uterus but retained a blood supply from the arcuate artery and vein which run along the lesser curvature of the uterine horn. The vessels were chilled, as before, to destroy peri-vascular nerves. In 2 additional pregnant ewes (Nos 2283 and 3008), the 
tubal extremity of the non-pregnant horn was partly isolated as described above, but the ovarian blood vessels were not chilled.

To confirm that momentary freezing of the blood vessels did not cause a permanent cessation of blood flow the experimental procedure was performed on both uterine horns of an anaesthetized ewe (not otherwise used in this study) and the chilled vessels were then cut. Blood flow from the chilled blood vessels appeared to be unimpaired. A similar acute experiment was performed on Ewe 2227 at the end of the recording period, and again the blood vessels supplying the isolated tissue proved to be patent.

\section{Histology}

Samples of myometrium from the transplanted segments and intact uterine horn were taken from 11 ewes representing the 3 experimental designs used (Table 1). Part of each sample was embedded in paraffin wax, sectioned at $8 \mu \mathrm{m}$ and stained with Masson's trichrome stain. The remaining tissue was sectioned on a cryostat and stained using the glyoxylic acid histofluorescence technique for the visualisation of catecholamines (de la Torre \& Surgeon, 1976).

Table 1. Details of experimental animals

\begin{tabular}{|c|c|c|c|c|c|c|}
\hline Ewe No. & Pregnant & $\begin{array}{c}\text { Gestational } \\
\text { age at } \\
\text { surgery } \\
\text { (days) }\end{array}$ & $\begin{array}{c}\text { Totally } \\
\text { isolated } \\
\text { transplant }\end{array}$ & $\begin{array}{c}\text { Partly } \\
\text { isolated } \\
\text { transplant }\end{array}$ & $\begin{array}{c}\text { Chilled } \\
\text { denervated } \\
\text { transplant }\end{array}$ & Histology§ \\
\hline B1 & - & & $\mathrm{T}$ & & & \\
\hline M1 & - & & $T^{*}$ & & & 21 \\
\hline M2 & - & & $T^{*}$ & & & 3 \\
\hline 18 & + & 47 & & $\mathrm{~T}$ & & \\
\hline 2241 & + & 115 & & $\mathrm{~T}$ & $\mathrm{~T}$ & $<1$ \\
\hline 703 & + & & & $\mathbf{T}$ & & \\
\hline 2043 & + & 125 & & $\mathrm{~T}$ & & $<1$ \\
\hline 2283 & + & 112 & & $\mathrm{~T}_{\ddagger}^{+}$ & & $<1$ \\
\hline 3008 & + & 128 & & $\mathrm{~T}_{\ddagger}^{\ddagger}$ & & $<1$ \\
\hline 2207 & + & 119 & $\mathbf{T}$ & & & 24 \\
\hline 2173 & + & 102 & $\mathrm{~T}, \mathrm{~B}, \mathrm{O}$ & & & $<1$ \\
\hline 831 & + & 124 & $T$ & & & \\
\hline 2209 & + & 119 & $\mathbf{T}, \mathbf{B}$ & & & 2 \\
\hline 2227 & + & 119 & & & $\mathbf{T}$ & 7 \\
\hline 2242 & + & 118 & & & $T^{+}$ & 7 \\
\hline 2215 & + & 133 & & & $T$ & $<1$ \\
\hline 2219 & + & 118 & & & $\mathrm{~T}$ & $<1$ \\
\hline 2233 & + & 127 & & & $\mathbf{T}$ & \\
\hline
\end{tabular}

$\mathrm{T}=$ tubal extremity $; \mathbf{B}=$ from body of uterus $; \mathrm{O}=$ oviduct $;^{*}=$ transplant in skin loop; $\dagger=$ blood supply from uterine vessels; $\ddagger \neq$ oviduct removed

$\S$ The number of days after the last recording that samples were taken.

\section{Plasma progesterone determination}

Blood was obtained from an indwelling jugular catheter in each of the non-pregnant ewes and was centrifuged at $1500 \mathrm{~g}$ for $15 \mathrm{~min}$ at $4^{\circ} \mathrm{C}$ immediately after collection. The separated plasma was stored frozen at $-15^{\circ} \mathrm{C}$ until assayed for progesterone by radioimmunoassay. Progesterone was assayed according to the method of Sernia, Hinds \& Biscoe (1980) using antiserum No. 334, kindly donated by Dr R. I. Cox, CSIRO Prospect, N.S.W., Australia. Cross-reactions of the antiserum with $11 \beta$-hydroxy-4-pregnene-3-one, pregnenolone or cortisol were $<1 \%$. The assay blank was 15 \pm 12 (s.e.m.) pg/tube. Intra- and inter-assay coefficients of variation were $12 \%$ and $9 \%$ 
respectively. The coefficient of correlation between progesterone added to ovine plasma and that recovered was $r^{2}=0.997(P<0.001)$.

\section{Analysis of data}

Data from the pregnant ewes were examined for evidence of a correlation between the EMG bursts recorded in the uterus and isolated tissues. The average frequency of bursts in the uterus and isolated tissue during the period of analysis was established and from these values the probability of coincidence of bursts at the two sites was calculated. An impulse burst was defined as having a

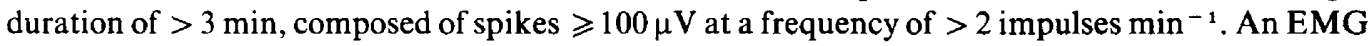
burst in the isolated myometrium was defined as coincident with a burst in the uterus when it started within 2 min of the start of the uterine EMG burst. Burst duration can be assumed to be 2 min when modelling coincidence because of the $\pm 2 \mathrm{~min}$ 'window' used in the definition. The probability of coincidence,

$$
P_{\mathrm{c}}=\left(\frac{60}{\mathrm{~F}_{\mathrm{ut}} \times 2}\right)^{-1} \times\left(\frac{60}{\mathrm{~F}_{1} \times 2}\right)^{-1}
$$

where $F_{u t}=$ burst frequency in uterus and $F_{i}=$ burst frequency in isolated tissue.

In the model, the mean duration of coincidence is $1 \mathrm{~min}$, so that $P_{\mathrm{c}}$ can be directly related to the expected frequency of coincidence $\left(E_{c}\right)$ per unit time. The observed frequency of coincidence, $\mathrm{O}_{c}$, was compared with $\mathrm{E}_{\mathrm{c}}$ using the $\chi^{2}$ test.

Data in the text are shown as means \pm s.d.

\section{Results}

\section{Tissue totally separated from uterus}

Non-pregnant ewes. Recordings were made from 3 non-pregnant ewes over a total of 6 oestrous cycles. Electrical activity was unpatterned and infrequent during the greater part of the luteal phase, when plasma progesterone levels exceeded $1 \mathrm{ng} \mathrm{ml}^{-1}$. However, in the isolated myometrium low-amplitude bursts $(50-100 \mu \mathrm{V})$ lasting 4-6 min and recurring 3-8 times per $\mathrm{h}$ were often detected (Text-fig. 2). Activity in the isolated myometrium initially appeared between 9 and 12 days after surgery. The amplitude and frequency of activity in the isolated myometrium and uterus started to increase 2-3 days before oestrus. In 5 of the 6 oestrous cycles this increase in activity coincided with a fall in plasma progesterone concentration. The EMG activity in the uterus and isolated tissue took the form of brief $(0 \cdot 5-2 \mathrm{~min})$ bursts of spikes which gradually increased in amplitude reaching a peak at oestrus. Uterine activity lasted for $80-100 \mathrm{~h}$ but returned to a low level before progesterone levels rose at the start of the subsequent luteal phase. Activity in the isolated tissue was not temporally related to EMG bursts in the uterus.

Post-mortem histological examination of the isolated tissue in 2 ewes 68 and 76 days after surgery showed no evidence of adrenergic reinnervation (P1. 1, Figs $1 \& 2$ ).

Pregnant ewes. Periodic EMG bursts lasting 4-10 min at a frequency of $1-4 \mathrm{~h}^{-1}$ appeared in the uterus from late gestation until term (145 days), confirming previous observations by Harding $e t$ al. (1982a). The entire myometrium became active during each burst and the resultant contraction raised IUP typically by $3-5 \mathrm{mmHg}$. In the $8-16$ days after surgery EMG activity in the isolated tissue was irregular and unpatterned, but gradually became organized into discrete bursts which resembled those in the intact uterus (Text-fig. 3). The mean duration of EMG bursts in the isolated tissue was $67 \%$ of those in the uterus (uterus $6.4 \pm 1.56 \mathrm{~min}$, isolated tissue $4.5 \pm 0.88 \mathrm{~min} ; n=10$ EMG bursts in each of 4 animals). The mean frequency of bursts in the isolated tissues of 4 animals during 6 recording periods totalling $59 \mathrm{~h}$ was $3.47 \pm 0.66 \mathrm{~h}^{-1}$, approximately double that of uterine activity $\left(1.78 \pm 0.97 h^{-1}\right)$. No temporal relationship was apparent between activity at the two sites 

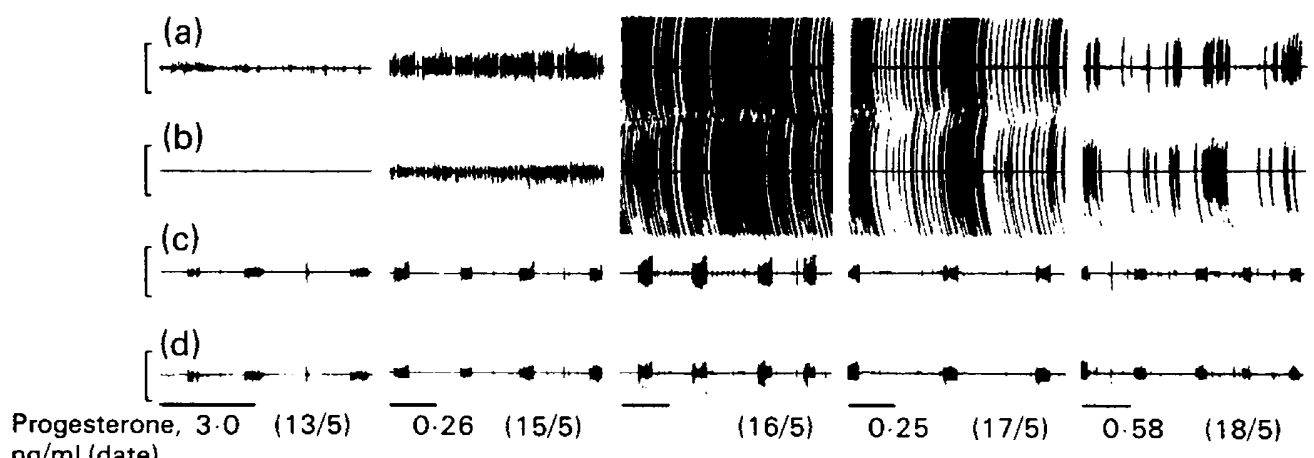
$\mathrm{ng} / \mathrm{ml}$ (date)
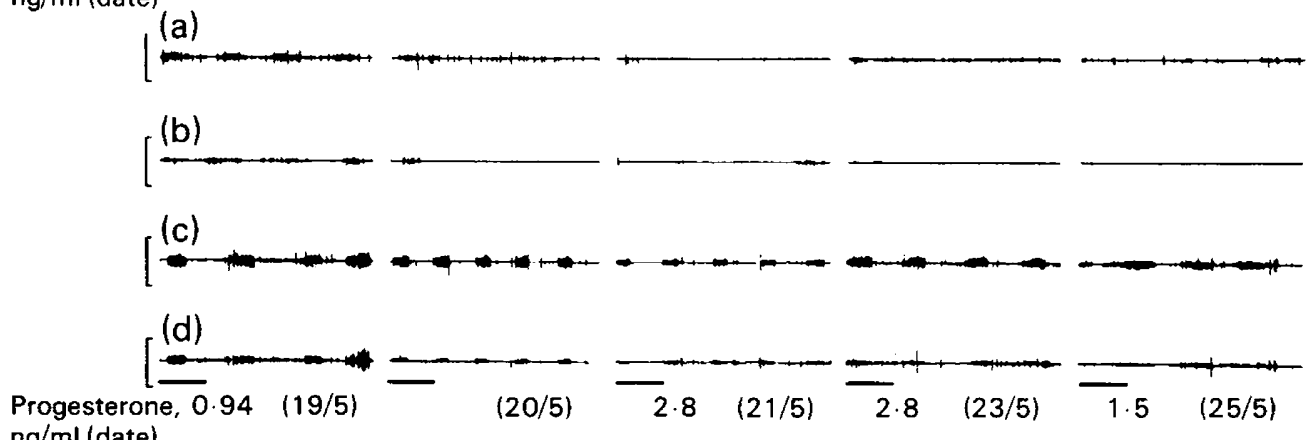
$\mathrm{ng} / \mathrm{ml}$ (date)

Text-fig. 2. EMG activity recording during part of 2 consecutive oestrous cycles in the right (a) and left (b) uterine horns, and from two sites on an isolated segment of tissue from the tubal extremity (c, d). In 2 sections of recordings from the uterine horns (16/5 and 17/5) the EMG signals have been limited in amplitude by the polygraph. Calibration for all channels: $500 \mu \mathrm{V}$, time bar $=10 \mathrm{~min}$.
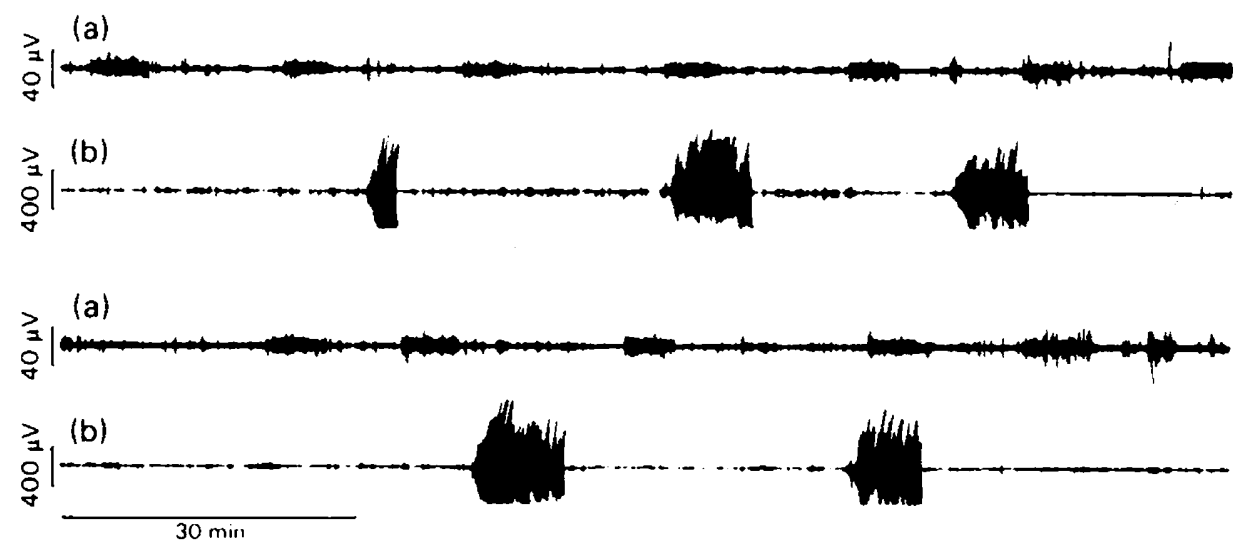

Text-fig. 3. EMG activity recorded at 120 days gestation from the base of the pregnant horn of the uterus (b), and a totally isolated piece of tissue from the tubal extremity (a).

and statistical analysis (Table 2) indicates that the observed numbers of coincident bursts were not significantly greater than those expected to occur by chance.

In one of the ewes in which two segments of myometrium were isolated (from the tubal extremity and uterine corpus) both transplants developed activity before parturition. Activity occurred independently in the two isolated tissues and did not coincide to a significant degree. 

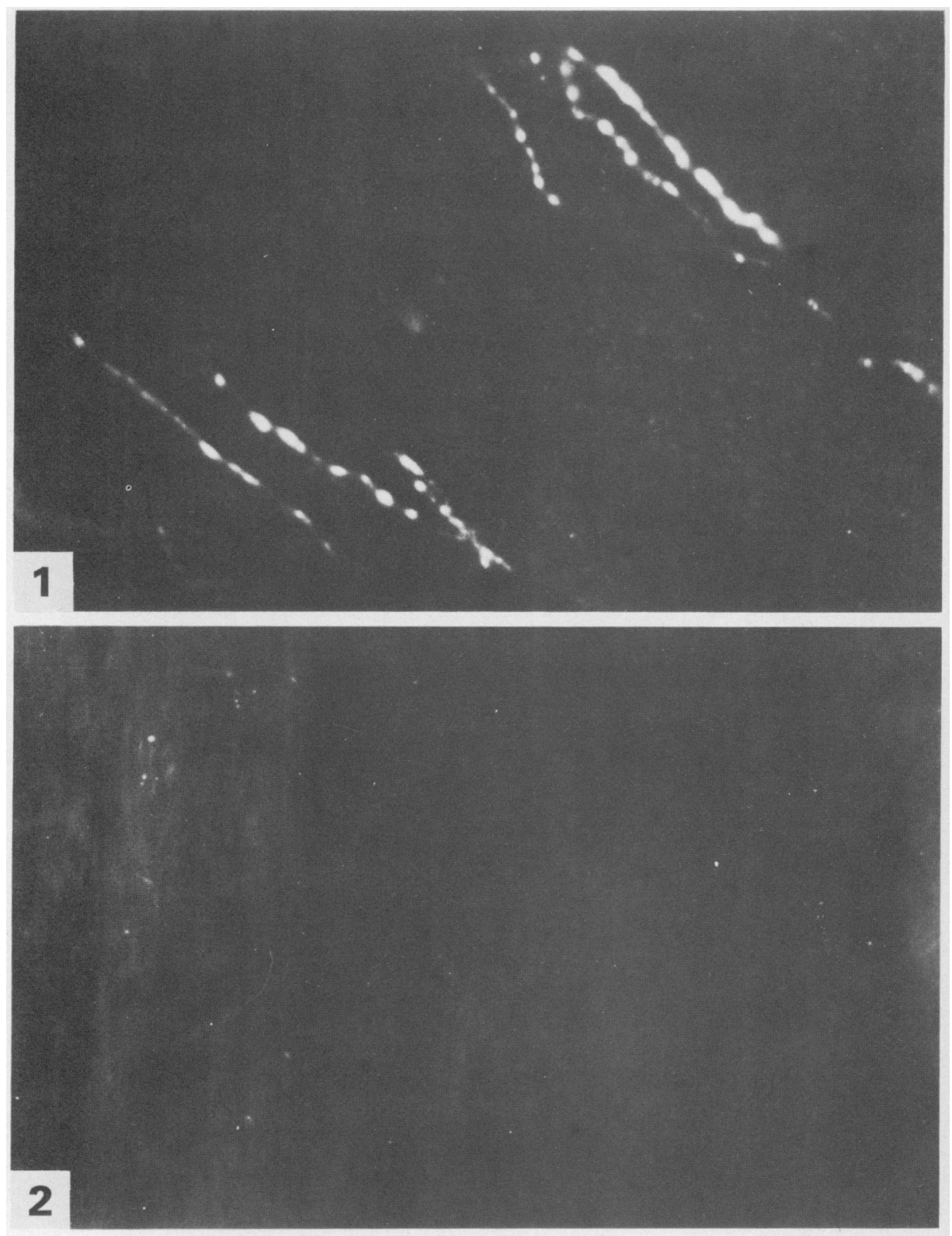

\section{$100 \mu \mathrm{m}$}

Fig. 1. Adrenergic axons in the longitudinat muscle of the intact tubal extremity of the uterus from a non-pregnant animal (glyoxylic acid histofluorescence).

Fig. 2. A section from the transplanted, totally isolated tubal extremity in the same animal. 68 days after surgery. Note that there has been no reinnervation of the tissue. 
Table 2. $\chi^{2}$ tests of association between observed $(\mathrm{O})$ and expected (E) number of coincident EMG bursts in uterus and transplanted tissue

\begin{tabular}{|c|c|c|c|c|c|c|c|}
\hline \multirow[b]{2}{*}{ Ewe No. } & \multirow{2}{*}{$\begin{array}{c}\text { Gestational } \\
\text { age } \\
\text { (days) }\end{array}$} & \multicolumn{2}{|c|}{ Frequency $h^{-1}$} & \multirow[b]{2}{*}{$\mathrm{E}$} & \multirow[b]{2}{*}{$\mathbf{O}$} & \multirow{2}{*}{$\begin{array}{l}\text { Observation } \\
\text { period (h) }\end{array}$} & \multirow[b]{2}{*}{$P$} \\
\hline & & Uterus & Transplant & & & & \\
\hline \multicolumn{8}{|c|}{ Totally isolated transplants } \\
\hline 2207 & 128 & $1 \cdot 17$ & $4 \cdot 17$ & 0.32 & $0 \cdot 16$ & 6 & NS \\
\hline 2207 & 129 & $2 \cdot 0$ & $4 \cdot 20$ & 0.56 & 0.6 & 5 & NS \\
\hline 2173 & 120 & 1.29 & $2 \cdot 82$ & 0.24 & 0.47 & $8 \cdot 5$ & NS \\
\hline $\begin{array}{l}831 \\
2209\end{array}$ & 135 & $3 \cdot 85$ & 3.85 & 0.99 & $1 \cdot 20$ & $8 \cdot 3$ & NS \\
\hline $\begin{array}{l}\text { (body) } \\
2209\end{array}$ & 133 & $1 \cdot 26$ & $2 \cdot 44$ & $0 \cdot 20$ & 0.44 & 27 & NS \\
\hline (tip) & 133 & $1 \cdot 29$ & 1.00 & 0.085 & 0.57 & 7 & NS \\
\hline \multicolumn{8}{|c|}{ Partly isolated transplants } \\
\hline 18 & 116 & $2 \cdot 87$ & $2 \cdot 25$ & 0.43 & $2 \cdot 25$ & 8 & $<0.01$ \\
\hline 18 & 127 & 1.06 & $1 \cdot 11$ & 0.08 & 1 & 18 & $<0.001$ \\
\hline 2241 & 120 & $1 \cdot 37$ & $2 \cdot 0$ & $0 \cdot 18$ & 1.375 & 8 & $<0.01$ \\
\hline 2241 & 127 & 1.50 & 1.75 & 0.175 & 1.5 & 8 & $<0.005$ \\
\hline 703 & & 1.73 & 1.91 & 0.22 & 1.73 & 22 & $<0.005$ \\
\hline 2043 & 130 & $3 \cdot 27$ & $3 \cdot 27$ & 0.71 & $3 \cdot 15$ & 8.25 & $<0.005$ \\
\hline $2283^{*}$ & 128 & 1.26 & 1.03 & 0.08 & 1.03 & 8.75 & $<0.005$ \\
\hline $3008^{*}$ & 134 & 3.96 & 3.58 & 0.95 & 3.58 & $5 \cdot 3$ & $<0.01$ \\
\hline $3008^{*}$ & 139 & $6 \cdot 75$ & $6 \cdot 25$ & $2 \cdot 81$ & $6 \cdot 25$ & 4 & $<0.05$ \\
\hline \multicolumn{8}{|c|}{ Chilled denervated transplants } \\
\hline 2227 & 122 & $2 \cdot 00$ & 4.00 & 0.53 & 0 & 5.5 & NS \\
\hline 2241 & 120 & $1 \cdot 37$ & 2.75 & 0.25 & 0.875 & 8 & NS \\
\hline 2241 & 126 & 1.28 & $2 \cdot 14$ & $0 \cdot 18$ & 0.5 & 14 & NS \\
\hline 2241 & 130 & 0.66 & 1.83 & 0.08 & 0.16 & 6 & NS \\
\hline 2242 & 124 & 3.05 & 5.0 & 1.01 & 1.65 & 20 & NS \\
\hline 2242 & 135 & 3.03 & 3.95 & 0.79 & 0.70 & 5.66 & NS \\
\hline 2242 & 142 & $2 \cdot 80$ & $5 \cdot 20$ & 0.97 & $1 \cdot 2$ & 5 & NS \\
\hline 2215 & 140 & 0.70 & 1.70 & 0.08 & $0 \cdot 1$ & 10 & NS \\
\hline 2215 & 145 & 0.54 & 1.73 & 0.062 & 0.27 & 11 & NS \\
\hline 2233 & 132 & $2 \cdot 33$ & 2.44 & 0.38 & 0.66 & 9 & NS \\
\hline 2219 & 124 & 1.42 & 1.56 & $0 \cdot 14$ & $1 \cdot 15$ & 19 & $<0.01$ \\
\hline 2219 & 126 & 0.95 & 1.53 & 0.09 & 0.79 & 19 & $<0.025$ \\
\hline
\end{tabular}

* Oviduct removed. Ewe 3008 was in early labour at 139 days.

Recordings were made from 3 of the ewes during parturition. During the 24-36 $\mathrm{h}$ period before parturition, the duration of EMG bursts in the uterus decreased, and their frequency and amplitude increased. A similar pattern of changes was seen in the isolated tissue (Text-fig. 4). A substantial increase in myoelectric activity, which occurred in the uterus at the time of delivery, also occurred in the transplanted segments (Text-fig. 5). In the ewe in which segments of myometrium were isolated from the oviduct, uterine body and tubal extremity, only the tubal extremity showed activity before parturition, but during labour and the post-partum period all three transplants exhibited independent patterns of activity. Post-mortem histological examination of the isolated tissues from this ewe showed no evidence of adrenergic re-innervation of the myometrium.

\section{Tissue partly isolated from uterus}

In the 4 pregnant ewes in which the isolated segments retained a connection with the uterus via the broad ligament and oviduct, $90 \%$ of the bursts in the isolated tissue occurred in synchrony with activity in the uterus (Text-fig. 6). The high degree of coincidence (Table 2) indicates that the 

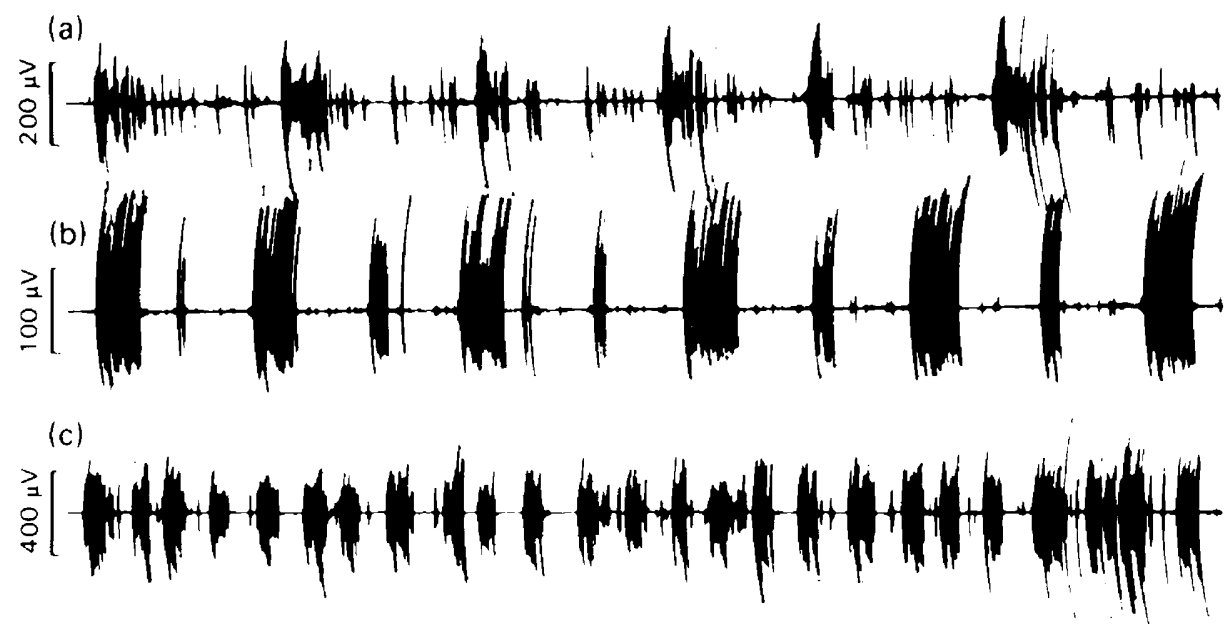

(d)

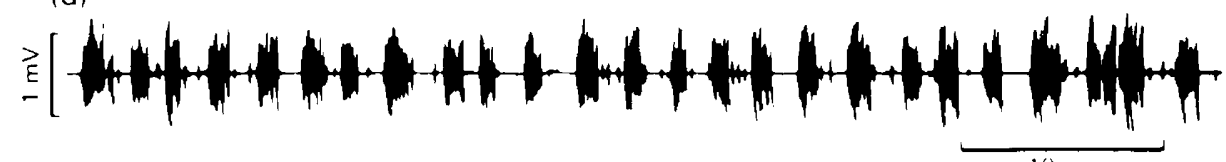

Text-fig. 4. EMG activity recorded during labour at two sites on a uterine horn (c = base of horn, $d=$ middle of horn) and from two pieces of isolated tissue removed from the body of the uterus (a) and tubal extremity (b).
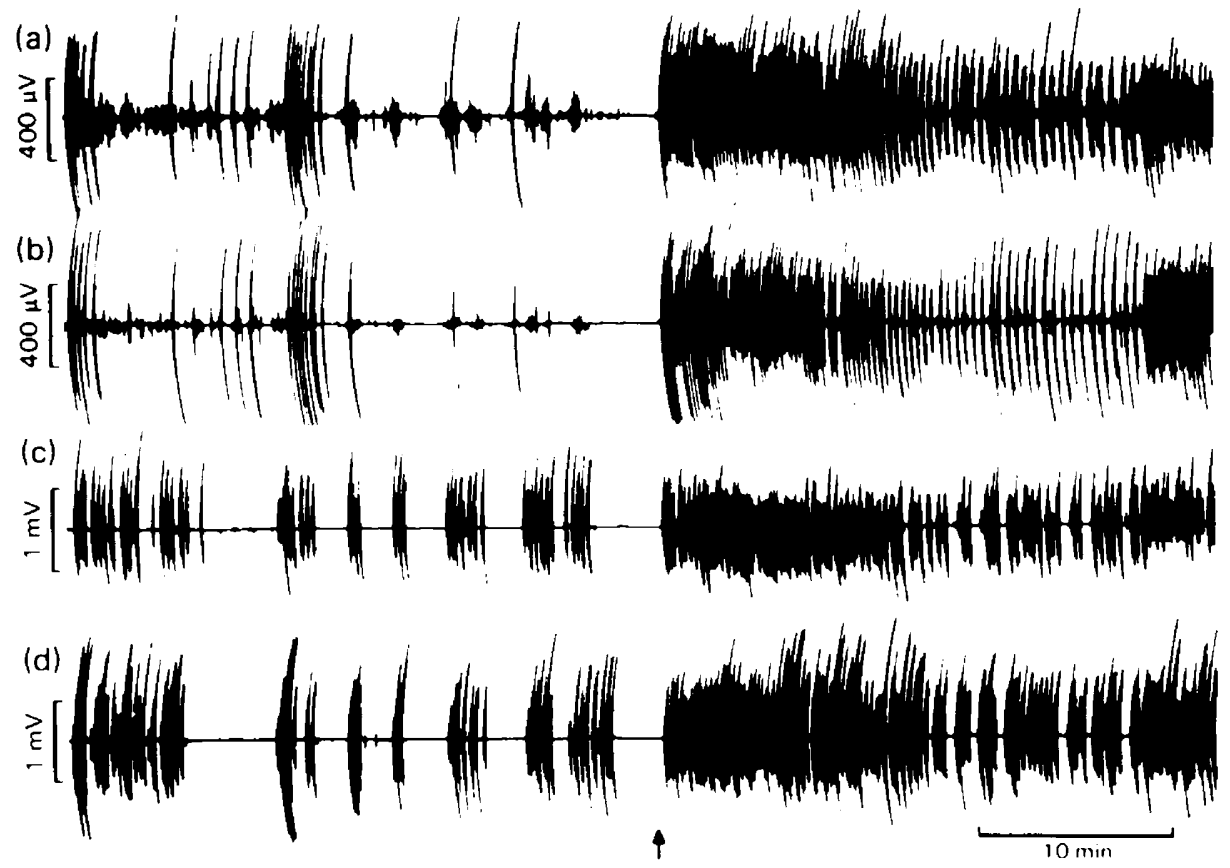

Text-fig. 5. Recordings spanning the time of delivery of a fetus. The arrow indicates the approximate time at which the head of the fetus emerged from the vagina. $(a, b)$ Two recording sites on isolated tissue from the tubal extremity of a horn. (c, d) Recording sites at the base (c) and mid region (d) of the pregnant uterine horn. 


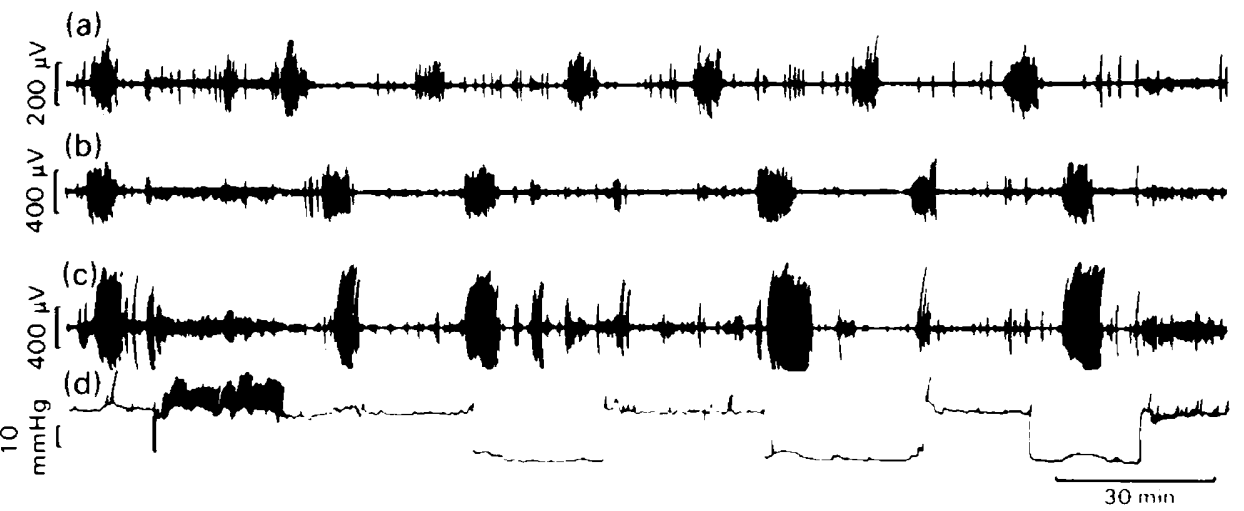

Text-fig. 6. EMG bursts in the uterus and two segments of partly isolated tissue from the tubal extremities of the uterine horns. One of the segments retained connections with the uterus via the oviduct and ovarian blood vessels (b). In the other segment the oviduct was removed and the ovarian vessels chilled (a). Note the relationship between EMG bursts in the uterus (c) and the bursts in the two segments. Step changes in intrauterine pressure (d) indicate changes in the position of the ewe from standing (higher level) to lying (lower level) and vice versa. The frequent transient increases in IUP soon after the start of the record are due to the ewe bleating.

activity at the two sites had a common origin, although the mean duration of bursts in the isolated tissues was slightly shorter $(6.50 \pm 1.45 \mathrm{~min})$ than that in the uteri $(7.07 \pm 1.56 \mathrm{~min}, n=92)$. The transplanted tissue and uterus of two animals were examined histologically. Peri-vascular adrenergic axons were present alongside the blood vessels supplying the isolated tissue, and a small number of adrenergic axons was seen in the myometrium of the transplant and at the tubal extremity of the unoperated horn. In Ewes 2283 and 3008 in which the isolated tissue was connected to the uterus by the ovarian vessels alone, all of the bursts in the isolated tissue occurred in synchrony with EMG activity in the uterus, a degree of coincidence significantly greater than would be expected from random association (Table 2). There was no histological evidence of an adrenergic innervation to the isolated tissue of these animals.

\section{Tissue partly isolated from uterus, blood vessels chilled}

This preparation was studied to determine whether the high level of coincidence observed in the activity of the uterus and partly isolated tissue was due to a uterotonic factor carried in the local utero-ovarian circulation. In 5 of the 6 ewes the activity of the transplanted tissue showed no temporal relationship with uterine contractions (Text-fig. 6) and the number of coincident EMG bursts was not significantly greater than would occur by random association (Table 2 ). In the 6th animal $62.5 \%$ of the bursts in the isolated tissue occurred in synchrony with activity in the uterus. Post-mortem histological examination of this animal and of 4 others showed that adrenergic axons were absent in the transplanted tissue and its associated blood vessels. The mean duration of the bursts in the isolated tissue $(5.04 \pm 0.91 \mathrm{~min})$ was $\sim 2 \mathrm{~min}$ less than the average burst in the uterus $(6.96 \pm 1.50 \mathrm{~min}, n=10$ in each of 6 animals). Discrete bursts initially appeared in the isolated tissue between 1 and 2 days after surgery.

\section{Discussion}

Multiple pacemaker sites in the myometrium were initially described by Marshall (1959) from experiments performed in vitro on progesterone-dominated rat uteri. More recent studies on the 
activity, in vivo, at parturition of human, pig and cow uteri have indicated that contractions can be initiated at more than one site on the uterus (Wolfs \& Rottinghuis, 1970; Sakaguchi \& Nakajima, 1973; Taverne et al., 1979a, b; Hanzen, 1981). Our studies of totally isolated transplants of myometrium demonstrate that uterine smooth muscle in vivo has an inherent rhythmicity which is not dependent upon an adrenergic innervation. Pacemaker sites are not limited to the tips of the uterine horns, but are also present in myometrium from the body of the uterus and it appears likely that myometrium isolated from any region of the uterus would be capable of developing rhythmic activity. Regular bursts of electrical activity were seen in transplanted tissues during the luteal and oestrous phases of the oestrous cycle, indicating that inherent rhythmicity is a property of both progesterone- and oestrogen-dominated myometrium. The high levels of oestrogen that occur at oestrus and at parturition (Moore et al., 1969; Challis et al., 1973; Challis \& Patrick, 1981) appear to be associated with an increase in frequency and a decrease in duration of the EMG bursts in the isolated tissues. The confluence of ovarian and uterine veins and lymph vessels in the mesometrium (Del Campo \& Ginther, 1973; Staples, Fleet \& Heap, 1982) will probably result in the exposure of the uterus to higher concentrations of oestrogen and progesterone than the isolated, transplanted tissue. If this is so, the presence of low amplitude bursts in the isolated tissue during the luteal phase, at a time when the uterus is quiescent, may be related to the different concentrations of progesterone to which the two sites are subjected.

The finding that EMG bursts in the isolated transplants are not in synchrony with uterine activity demonstrates that uterine contractions during oestrus and pregnancy are not co-ordinated by a uterotonic factor carried in the systemic circulation. However, at parturition it is clear that circulating factors (possibly prostaglandins or oxytocin) have a profound effect on uterine activity as demonstrated by the large and simultaneous increase in activity in the uterus and transplant at the time of birth.

What then, is responsible for co-ordinating the activity of a multitude of individual pacemaker sites in the myometrium to produce regular uterine contractions and the associated rise in IUP? The activity recorded in the partly isolated non-chilled tubal extremity could be synchronized with uterine contractions in one or more of the following ways: by impulse propagation along smooth muscle in the broad ligament, by nerves running in the oviduct and alongside ovarian blood vessels, by the stretching effect of fluid moving from the active portion towards a quiescent region (Takeda, 1965) or by a uterotonic factor released by the contraction of one area of the uterus into the local uterine circulation. This latter mechanism was considered to be a possibility because of evidence of a reduction during pregnancy in the density of the adrenergic uterine innervation of the ewe (Sigger \& Parkington, 1983) and a fall in the noradrenaline content of the uterus (J. F. Padbury, C. J. Hobel \& D. A. Fisher, unpublished observations) similar to that described for the guinea-pig (Thorbert, 1979).

Data from the experiments in which tissue was partly isolated from the uterus, and in which the ovarian vessels were not chilled, demonstrates that hydraulic continuity within the uterus, for example via amniotic and allantoic fluids, is not required to maintain co-ordinated activity as was suggested by Takeda (1965). Evidence from Ewes 2283 and 3008, in which the tubal extremity remained attached to the uterus by the ovarian vessels alone, suggests that an adrenergic innervation is not necessary to maintain synchrony between the uterus and the partly isolated tissue. In these 2 animals there was no evidence of adrenergic axons in the operated tubal extremity even though the blood vessels supplying this tissue had not been chilled. Much of the adrenergic innervation of the tubal extremities arrives via the oviducts (J. N. Sigger, unpublished observations) and the removal of the oviduct is the probable reason for the absence of innervation.

The third type of experimental preparation was studied to test the 'local factor' hypothesis by partly isolating and purposely denervating the tip of the horn whilst leaving its blood supply from the ovarian or uterine blood vessels intact. The maintenance of the blood supply after chilling the vessels was confirmed by acute experiments on 2 ewes. Indirect evidence of a continuing circulation in the other ewes is provided by visual observations of reddening of the isolated tissue 
soon after chilling and by the first recordings of EMG bursts 1-2 days after surgery in these experiments in comparison with 8-16 days in the totally isolated transplants which were initially avascular. In addition, histological examination of the chilled denervated transplants showed no discernible disruption to the smooth muscle layers of the myometrium whereas the smooth muscle of the totally isolated transplants had no regular orientation.

Recordings from the chilled denervated myometrium showed EMG bursts out of phase with those in the uterus in the majority of animals, which indicates that uterine activity is not coordinated by substances carried locally in the utero-ovarian circulation. The presence of in-phase activity in the non-chilled, partly isolated tissue of Ewes 2283 and 3008, in which no adrenergic innervation was visible, was probably due to impulse propagation along the smooth muscle of the small amount of broad ligament which remained alongside the blood supply. The chilling technique used in the third experimental preparation is likely to have disrupted impulse conduction along perivascular tissue, and this may account for the lack of synchrony between the uterus and the operated tissue in these animals.

In-vitro studies of progesterone-dominated myometrium from small laboratory animals have shown there is a decrease in spontaneous activity and an increase in tissue resistance in comparison to oestrogen-dominated myometrium (Ichikawa \& Bortoff, 1970; Daniel \& Lodge, 1973). Little is known about the spread of activity in the intact uterus in vivo. In the late pregnant sheep uterus, stimulus pulses of long duration $(>1 \mathrm{sec}$ ) and high intensity were required to evoke action potentials, which were recorded at sites $4 \mathrm{~cm}$ from the stimulating electrodes, but not at $8 \mathrm{~cm}$ (Sigger \& Harding, 1983). From the available evidence it therefore appears unlikely that impulses propagate over the entire surface of the pre-parturient uterus although it is possible that impulse propagation is sufficient to cause coupling between pacemaker sites. Models of coupled non-linear oscillators in the gastro-intestinal tract (which resemble myometrial pacemakers) show that, if oscillators with a high intrinsic frequency are coupled to oscillators of low intrinsic frequency, the overall frequency of activity will be somewhere between the two oscillation frequencies (Daniel \& Sarna, 1978). Our data show that the intrinsic frequency of all except one totally isolated myometrial transplant was equal to or higher than that of the uterus, and in the virtual absence of isolated tissue segments having activity at a lower frequency it is difficult to accept the notion of coupled oscillators in the uterus. The high circulating levels of oestrogen and the appearance of numerous gap junctions in the myometrium at the time of parturition (Garfield, Rabideau, Challis \& Daniel, 1979) may allow impulses to propagate over greater distances than in the pre-parturient uterus. Under these conditions impulse propagation through the myometrium is likely to play a major role in the co-ordination of uterine activity.

We are grateful for support provided by the National Health and Medical Research Council. We also thank Professor G. D. Thorburn for encouragement and useful discussions, and Miss Jenny Buttress for valuable assistance with the care of the experimental animals.

\section{References}

Challis, J.R.G. \& Patrick, J.E. (1981) Fetal and maternal oestrogen concentrations throughout pregnancy in the sheep. Can. J. Physiol. Pharmacol. 59, 970-978.

Challis, J.R.G., Davies, I.J. \& Ryan, K.J. (1973) Concentration of progesterone, estrone and estradiol-17 $\beta$ in plasma of pregnant rabbits. Endocrinology 93, 971975.

Csapo, A. \& Sauvage, J. (1968) The evolution of uterine activity during human pregnancy. Acta obstet. gynec. scand. 47, 181-212.

Daniel, E.E. \& Lodge, S. (1973) Electrophysiology of myometrium. In Uterine Contraction-Side Effects of Steroidal Contraceptives, pp. 19-64. Ed. J. B. Josimovich. John Wiley, New York.

Daniel, E.E. \& Sama, S. (1978) The generation and conduction of activity in smooth muscle. Ann. Rev. Pharmacol. Toxicol. 18, 145-166.

de la Torre, J.C. \& Surgeon, J.W. (1976) A methodological approach to rapid and sensitive monoamine histofluorescence using a modified glyoxylic acid technique: the SPG method. Histochemistry 49, 8193. 
Del Campo, C.H. \& Ginther, O.J. (1973) Vascular anatomy of the uterus and ovaries and the unilateral luteolytic effect of the uterus: angioarchitecture in sheep. Am. J. vet. Res. 34, 1377-1385.

Garfield, R.E., Rabideau, S., Challis, J.R.G. \& Daniel, E.E. (1979) Hormonal control of gap junction formation in sheep myometrium during parturition. Biol. Reprod. 21, 999-1007.

Germain, G., Cabrol, D., Visser, A. \& Sureau, C. (1982) Electrical activity of the pregnant uterus in the cynomolgus monkey. Am. J. Obstet. Gynec. 142, 513 519.

Hanzen, C. (1981) Electrical activity of the bovine uterus prior to, and post-parturition. Vet. Res. Commun. 5, $143-150$.

Harding, R., Poore, E.R., Bailey, A., Thorburn, G.D., Jansen, C.A.M. \& Nathanielsz, P.W. (1982a) Electromyographic activity of the non-pregnant and pregnant sheep uterus. Am. J. Obstet. Gynec. 142, 448457.

Harding, R., Jenkin, G. \& Sigger, J.N. (1982b) The relationship between electrical activity of transplanted and in situ myometrium in the non-pregnant ewe. Proc. Aust. Physiol. Pharmacol. Soc. 13, 170P, Abstr.

Hindson, J.C. \& Ward, W.R. (1973) Myometrial studies in the pregnant sheep. In The Endocrinology of Pregnancy and Parturition, pp. 153-170. Ed. C. G. Pierrepoint. Alpha Omega Alpha, Cardiff.

Ichikawa, S. \& Bortoff, A. (1970) Tissue resistance of the progesterone dominated rabbit myometrium. Am. J. Physiol. 219, 1763-1767.

Marshall, J.M. (1959) Effects of estrogen and progesterone on single uterine muscle fibres in the rat. $A m . J$. Physiol. 197, 935-942.

Marshall, J.M. (1962) Regulation of activity in uterine smooth muscle. Physiol. Rev. 42, 213-227.

Marshall, J.M. (1981) Effects of ovarian steroids and pregnancy on adrenergic nerves of uterus and oviduct. Am. J. Physiol. 240, C165-C174.

Moore, N.W., Barrett, S., Brown, J.B., Schindler, I., Smith, M.A. \& Smyth, B. (1969) Oestrogen and progesterone content of ovarian vein blood of the ewe during the oestrous cycle. J. Endocr. 44, 55-62.
Nathanielsz, P.W., Bailey, A., Poore, E.R., Thorburn, G.D. \& Harding, R. (1980) The relationship between myometrial activity and sleep state and breathing in fetal sheep throughout the last third of gestation. $\mathrm{Am}$. J. Obstet. Gynec. 138, 653-659.

Porter, D.G. (1971) Quantitative changes in myometrial activity in the guinea-pig during pregnancy. $J$. Reprod. Fert. 27, 219-226.

Sakaguchi, M. \& Nakajima, A. (1973) Electromyogram of the human uterus in labour. J. appl. Physiol. 35, 423-426.

Sernia, C., Hinds, L. \& Tyndale-Biscoe, C.H. (1980) Progesterone metabolism during embryonic diapause in the tammar wallaby, Macropus eugenii. J. Reprod. Fert. 60, 139-147.

Sigger, J.N. \& Harding, R. (1983) Limited propagation of EMG activity in the myometrium of the sheep during late pregnancy. Aust. Paediatr. (in press).

Sigger, J.N. \& Parkington, H. (1983) Changes in uterine innervation during pregnancy. Excerpta Medica Asia Pacific Congress Series No. 14, 23-24.

Staples, L.D., Fleet, I.R. \& Heap, R.B. (1982) Anatomy of the utero-ovarian lymphatic network and the composition of afferent lymph in relation to the establishments of pregnancy in the sheep and the goat. J. Reprod. Fert. 64, 409-420.

Takeda, H. (1965) Generation and propagation of uterine activity in situ. Fert. Steril. 16, 113-119.

Taverne, M.A.M., Naaktegeboren, C., Elsaesser, F., Forsling, M.L., van der Weyden, G.C., Ellendorff, F. \& Smidt, D. (1979a) Myometrial electrical activity and plasma concentrations of progesterone, estrogens and oxytocin during late pregnancy and parturition in the miniature pig. Biol. Reprod. 21, 1125-1134.

Taverne, M.A.M., Naaktegeboren, C. \& van der Weyden, G.C. (1979b) Myometrial activity and expulsion of fetuses. Anim. Reprod. Sci. 2, 117-131.

Thorbert, G. (1979) Regional changes in structure and function of adrenergic nerves in guinea-pig uterus during pregnancy. Acta obstet. gynec. scand., Suppl. 79, 5-32.

Wolfs, G. \& Rottinghuis, H. (1970) Electrical and mechanical activity of the human uterus during labour. Arch. Gynak. 208, 373-385.

Received 21 April 1983 